\title{
Successful hybrid coronary artery revascularisation in a patient with severe cerebrovascular disease: a new treatment option to minimise the risk of stroke
}

\author{
Abhinay Challa, ${ }^{1}$ Elizabeth Shaw, ${ }^{1}$ Peter Pohlner, ${ }^{2}$ Christopher Raffel $^{1}$
}

${ }^{1}$ Cardiology, The Prince

Charles Hospital, Chermside,

Queensland, Australia

${ }^{2}$ Cardiothoracic Surgery,

The Prince Charles Hospital,

Brisbane, Queensland, Australia

\section{Correspondence to}

Dr Abhinay Challa,

abhinay.challa@hotmail.com

Accepted 8 May 2017

CrossMark

To cite: Challa $A$, Shaw $E$, Pohlner P, et al. BMJ Case Rep Published Online First: [please include Day Month Year]. doi:10.1136/bcr-2016 218603

\section{SUMMARY}

Here we present a case involving a patient with severe distal left main coronary artery stenosis with extensive coexisting extracranial cerebrovascular disease where hybrid coronary artery revascularisation was successfully performed. This illustrates the potential for hybrid revascularisation in those patients with an inherit risk of stroke.

\section{BACKGROUND}

Coronary artery bypass surgery (CABG) is the treatment of choice for patients with severe unprotected left main coronary artery disease. CABG does however expose patients to a higher risk of cerebrovascular accidents (CVAs) when compared with percutaneous coronary intervention (PCI).

The emergence of hybrid coronary artery revascularisation provides a promising treatment alternative for patients, particularly those with a predisposition to cerebrovascular complications. By using off-pump CABG, patients are not exposed to the risk of cardiopulmonary bypass and have a reduced risk of postoperative stroke by up to $30 \%$ when compared with conventional on-pump surgery. The decision for CABG or PCI in patients with left main coronary artery disease is still of debate, and here we discuss recent landmark trials and its implications on clinical practice.

\section{CASE PRESENTATION}

A 49-year-old man with a history of an ATS aortic valve replacement (AVR) and single-vessel right internal mammary artery (RIMA) to right coronary artery bypass performed 9 years ago was referred by his general practitioner with increasing episodes of chest pain over the last 5 months. He was using lifelong warfarin for his AVR and had a history of transient ischaemic attacks and known carotid stenosis, with a left internal carotid artery stent inserted the year prior. A myocardial perfusion scan was positive for ischaemia in the anteroseptal region.

\section{INVESTIGATIONS}

On angiography a new 90\% distal left main coronary artery (LMCA) stenosis, associated with severe stenosis of the ostia of the left anterior descending artery (LAD) and circumflex artery (figure 1), was noted. His previous RIMA graft to right coronary artery was patent on angiography.

\section{TREATMENT}

He was referred for CABG; however, extracranial arterial assessment revealed total occlusion of bilateral internal carotid arteries and the left vertebral artery. Given the extensive extracranial cerebrovascular disease, on-pump CABG was deemed too high risk.

After discussion between cardiology and cardiothoracic teams, a hybrid revascularisation approach was considered most appropriate, and the patient successfully underwent off-pump CABG. With concerns of adhesions from his previous sternotomy, and potential vascular injury to his pre-existing RIMA graft, a lateral left thoracotomy approach was used rather than a sternal approach to access the LAD circulation.

There was severe stenosis of the left subclavian artery origin, resulting in the left internal mammary artery (LIMA) flow being highly uncertain. Furthermore, the LIMA was found to have very poor forward flow, with continued poor flow despite progressively transecting the artery towards its origin; thus, a venous graft was used.

The descending thoracic aorta was thickened but with minimal disease, and readily accessed from an anterolateral thoracotomy, and therefore was suitable for vein inflow attachment. The first diagonal artery was more than $1.5 \mathrm{~mm}$ without significant atheroma, with no obstruction between the diagonal and the LAD, and deemed suitable for attachment of the vein graft to provide flow into the LAD territory. A saphenous venous graft (SVG) was used and anastomosed from the descending thoracic aorta to the first diagonal artery.

Postoperatively, the patient had labile blood pressure and a dopamine infusion was initiated, and the patient was transferred to the intensive care unit. Extubation was uncomplicated and the dopamine infusion was weaned within 2 days after the operation, with the patient subsequently being transferred to the ward.

Following demonstration of patency of the SVG to the first diagonal artery, which had retrograde flow to the LAD through CT coronary angiogram (figure 2), which was also demonstrated by angiography (video 1), PCI with rotational atherectomy was performed 12 days after the off-pump procedure.

The LMCA was engaged using a 7Fr EBU 3.5 (Medtronic) guide catheter. Rotablation was 


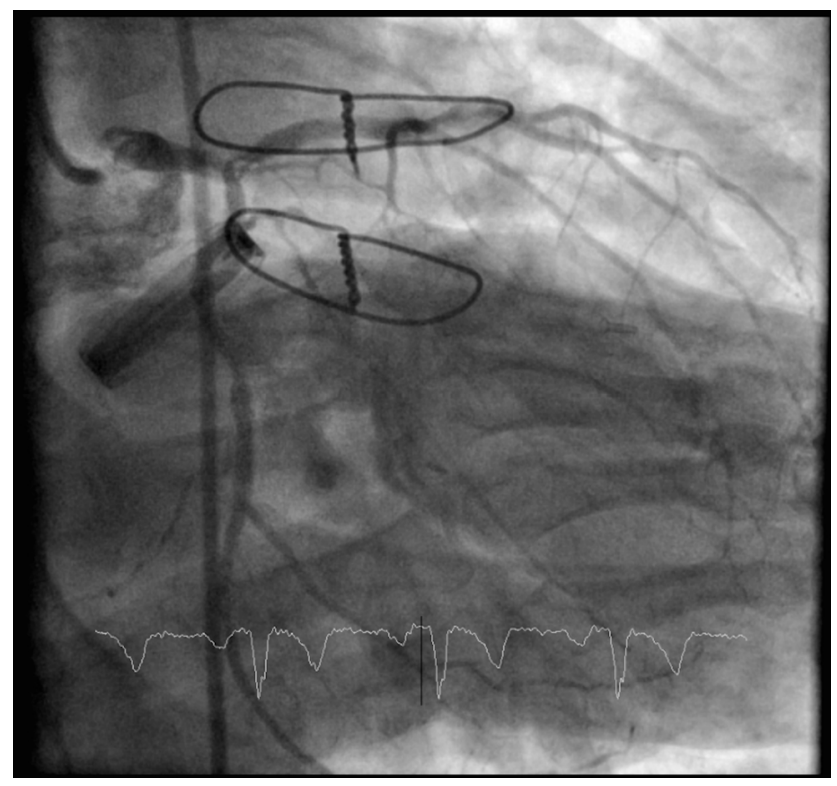

Figure 1 Angiogram showing $90 \%$ left main coronary artery stenosis.

performed using a ChoICE Extra Support (Boston Scientific) 0.009 in by $325 \mathrm{~cm}$ guidewire over five passes, with a $1.5 \mathrm{~mm}$ burr at $165 \mathrm{rpm}$. A Vision RX (Abbott) $4.0 \times 12 \mathrm{~mm}$ bare-metal stent was deployed with intravascular ultrasound used to guide stent deployment and apposition. On final imaging the LAD was jailed with TIMI 2 flow (video 2), and as such prevented

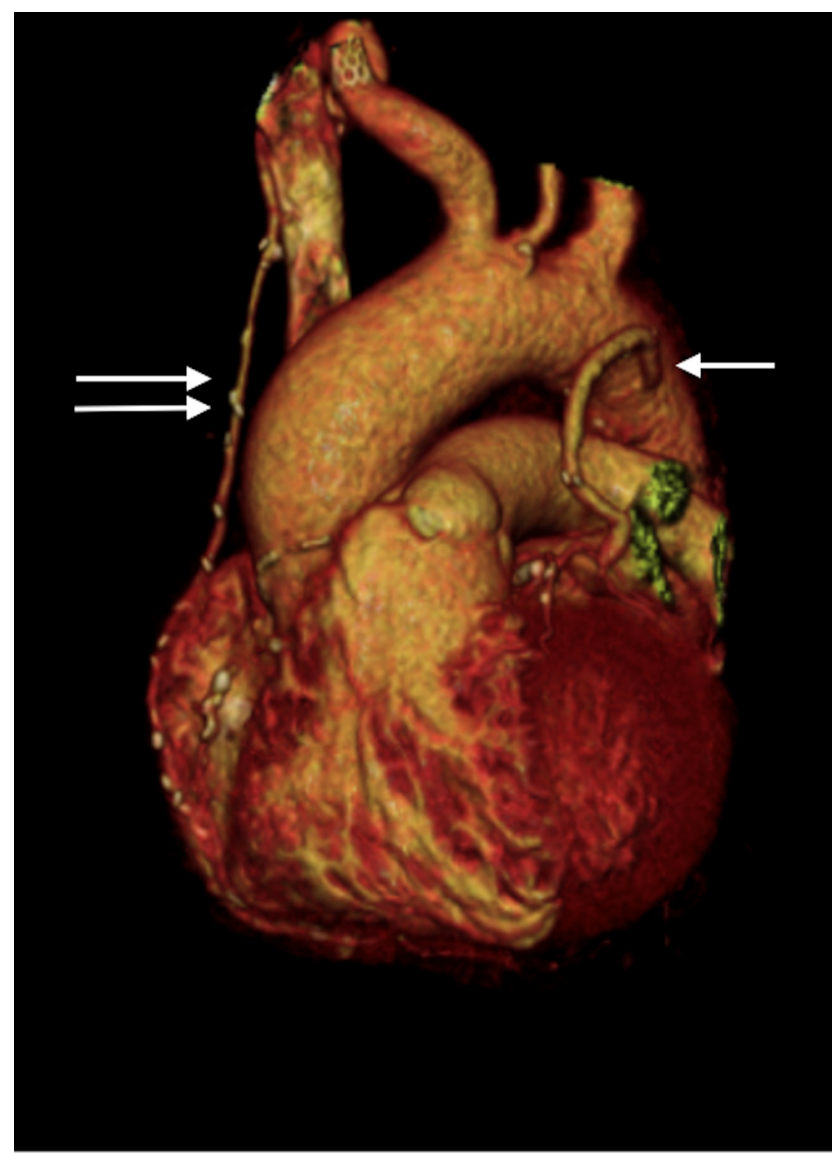

Figure 2 Right internal mammary artery to right coronary artery graft (double arrows) and aorta to first diagonal graft (single arrow).

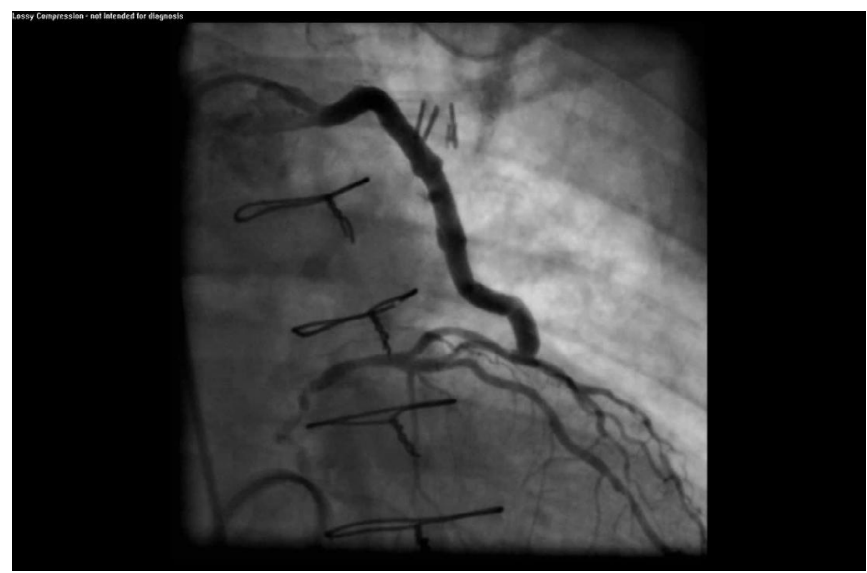

Video 1 Angiogram showing the patient's saphenous venous graft from the aorta to the first diagonal with retrograde flow into the left anterior descending artery.

competitive flow that could compromise the recently implanted SVG graft. The procedure was uncomplicated and the patient was discharged home 2 days later.

\section{OUTCOME AND FOLLOW-UP}

The patient had no further myocardial infarctions and no cardiac admissions to hospital for 5 years after the hybrid procedure, and did not have any symptoms of stable angina. Furthermore he had no cerebral events related to his vascular disease or mechanical valve.

\section{DISCUSSION}

The current treatment of choice for individuals with unprotected left main disease is CABG as opposed to PCI. ${ }^{1}$ The benefit of CABG on long-term mortality is debatable ${ }^{2}$; however, there is consensus that there is a definite reduction in the need for target vessel revascularisation (TVR) and lower major adverse cardiac events in patients undergoing $\mathrm{CABG},{ }^{3}$ making it the procedure of choice in unprotected left main disease. On the other hand, the risk of CVAs is significantly higher in those undergoing CABG compared with PCI. ${ }^{4}$

To date, there have only been few large randomised controlled trials comparing CABG and PCI in patients with unprotected left main disease. The SYNTAX study included a subgroup analysis of patients with unprotected left main disease, and did not show a statistically significant difference in their primary composite

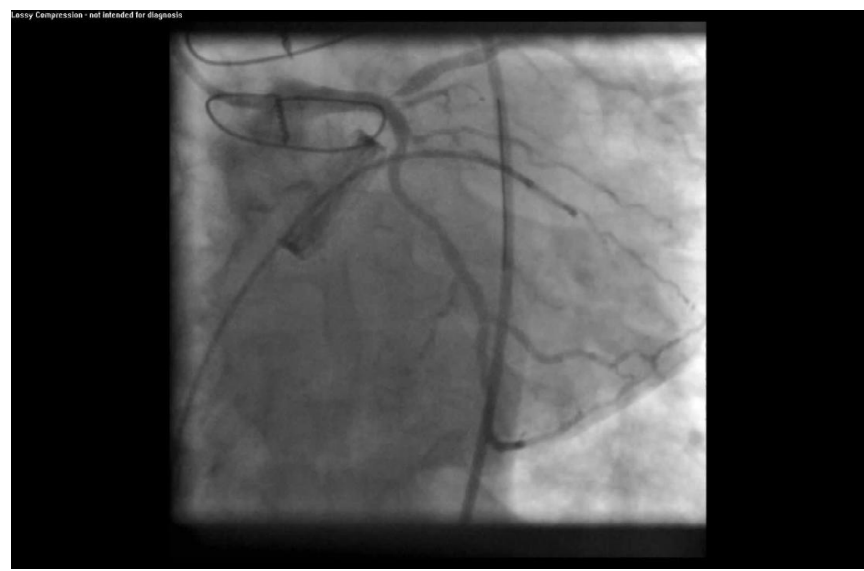

Video 2 Angiogram postdistal left main coronary artery stenting. 
endpoint of major adverse cardiac or cerebrovascular events. The study was significant for higher rates of TVR in the PCI group and higher rates of stroke in the CABG group.

The NOBEL and EXCEL studies were two randomised controlled trials that looked specifically at patients with left main disease. The EXCEL trial had a mean follow-up of 3 years with a primary composite endpoint of death, stroke and myocardial infarction, including perioperative infarcts. The trial showed non-inferiority of PCI to CABG for left main disease at 30 days and at 3 years in their primary outcome, but a statistically significant increase in TVR and periprocedural myocardial infarctions in the PCI group. There was no difference in stroke or all-cause mortality between groups; however, there was a trend towards increased mortality in the PCI group at 3 years, which did not reach statistical significance. ${ }^{6}$

The NOBLE trial followed up patients for up to 5 years, and did not include periprocedural myocardial infarctions in their primary composite endpoint. It showed statistically significant lower major adverse cardiovascular and cerebrovascular events for patients undergoing CABG, with non-procedural myocardial infarctions higher in the PCI group and no difference in all-cause mortality. The study was significant for higher rates of stroke in the CABG group at 30 days and higher rates of TVR in the PCI group.

These two studies do not unanimously show superiority of CABG or PCI in unprotected left main disease, and re-enforce what was illustrated by the SYNTAX study that patients will have higher rates of stroke when undergoing CABG, which is offset by a higher rate of TVR in PCI with no significant reduction in all-cause mortality.

However, the advantage of lower TVR in patients undergoing CABG begins to be outweighed by the risk of CVA in patients with carotid stenosis. ${ }^{8}$ Off-pump CABG can reduce the risk of postoperative stroke by up to $30 \%$ when compared with conventional $\mathrm{CABG},{ }^{9}$ providing an alternative treatment option in patients with an inherent high risk of CVA.

The introduction of minimally invasive off-pump CABG provides patients with the benefits of bypass surgery without the significant risks of cardiopulmonary bypass, such as bleeding, infection and adverse neurological events. ${ }^{10}$ Off-pump coronary artery surgery is used primarily for LIMA to LAD anastomosis, as the LIMA and LAD can be directly visualised from a minithoracotomy. When performed with on-pump CABG, studies have shown the LIMA to LAD anastomosis can have up to a $96 \%$ graft patency at 10 years. ${ }^{11}$

A case series study that discusses the morbidity of patients undergoing hybrid off-pump CABG and PCI to non-LAD lesions

\section{Learning points}

- There is ongoing debate on whether coronary artery bypass surgery is superior to percutaneous coronary intervention for patients with left main coronary artery disease.

- Percutaneous coronary intervention allows for lower rates of stroke.

- Coronary artery bypass has the benefit of less requirements of target vessel revascularisation.

- Hybrid off-pump coronary artery surgery with percutaneous intervention to non-left anterior descending lesions provides the potential advantage of the longevity of an arterial graft to anterior circulation, while minimising the risk of stroke. showed short-term procedural feasibility. ${ }^{12}$ This study does not however address the long-term viability and risks of such procedures, which include an increased overall rate of graft occlusion, particularly with use of SVG, as well as an increase in late (more than 1 year) all-cause mortality by $37 \%$ in off-pump CABG when compared with on-pump CABG. ${ }^{13} 14$

In patients with left main disease and a high risk of CVA, hybrid off-pump CABG with PCI to the left main coronary artery is promising. Currently there is no consensus on whether CABG or PCI is superior in left main disease, and hybrid revascularisation provides a treatment alternative in patients with a high risk of stroke, while providing the benefit of the durability of an arterial graft.

Contributors Literature review and case report written by AC. Reviewed by CR and ES, who elaborated on technical aspects of percutaneous intervention, as well as PP who provided insights regarding off-pump CABG and specifics regarding the operation.

Competing interests None declared.

Patient consent Obtained.

Provenance and peer review Not commissioned; externally peer reviewed.

(c) BMJ Publishing Group Ltd (unless otherwise stated in the text of the article) 2017. All rights reserved. No commercial use is permitted unless otherwise expressly granted.

\section{REFERENCES}

1 Eagle KA, Guyton RA, Davidoff R, et al. ACC/AHA 2004 guideline update for coronary artery bypass graft surgery: summary article: a report of the American College of Cardiology/American Heart Association Task Force on Practice Guidelines (Committee to Update the 1999 Guidelines for Coronary Artery Bypass Graft Surgery). Circulation 2004;110:1168-76.

2 Jang JS, Choi KN, Jin HY, et al. Meta-analysis of three randomized trials and nine observational studies comparing drug-eluting stents versus coronary artery bypass grafting for unprotected left main coronary artery disease. Am J Cardiol 2012;110:1411-8

3 Sá MP, Soares AM, Lustosa PC, et al. Meta-analysis of 5,674 patients treated with percutaneous coronary intervention and drug-eluting stents or coronary artery bypass graft surgery for unprotected left main coronary artery Stenosis. Eur J Cardiothorac Surg 2013;43:73-80.

4 Palmerini T, Biondi-Zoccai G, Reggiani LB, et al. Risk of stroke with coronary artery bypass graft surgery compared with percutaneous coronary intervention. J Am Coll Cardiol 2012:60:798-805

5 Mohr FW, Morice MC, Kappetein AP, et al. Coronary artery bypass graft surgery versus percutaneous coronary intervention in patients with three-vessel disease and left main coronary disease: 5 -year follow-up of the randomised, clinical SYNTAX trial. Lancet 2013;381:629-38.

6 Stone GW, Sabik JF, Serruys PW, et al. Everolimus-Eluting stents or bypass surgery for left main coronary artery disease. N Engl J Med 2016;375:2223-35.

7 Mäkikallio T, Holm NR, Lindsay M, et al. Percutaneous coronary angioplasty versus coronary artery bypass grafting in treatment of unprotected left main Stenosis (NOBLE): a prospective, randomised, open-label, non-inferiority trial. Lancet 2016;388:2743-52.

8 Tarakji KG, Sabik JF, Bhudia SK, et al. Temporal onset, risk factors, and outcomes associated with stroke after coronary artery bypass grafting. JAMA 2011;305:381-90.

9 Afilalo J, Rasti M, Ohayon SM, et al. Off-pump vs. on-pump coronary artery bypass surgery: an updated meta-analysis and meta-regression of randomized trials. Eur Heart J 2012:33:1257-67.

10 DeRose JJ. Current state of integrated "hybrid" coronary revascularization. Semin Thorac Cardiovasc Surg 2009;21:229-36.

11 Shah PJ, Durairaj M, Gordon I, et al. Factors affecting patency of internal thoracic artery graft: clinical and angiographic study in 1434 symptomatic patients operated between 1982 and 2002. Eur J Cardiothorac Surg 2004;26:118-24.

12 Modrau IS, Nielsen PH, Bøtker HE, et al. Feasibility and early safety of hybrid coronary revascularisation combining off-pump coronary surgery through J-hemisternotomy with percutaneous coronary intervention. Eurolntervention 2015; 10:e1-e6.

13 Takagi H, Matsui M, Umemoto T. Lower graft patency after off-pump than on-pump coronary artery bypass grafting: an updated meta-analysis of randomized trials. $J$ Thorac Cardiovasc Surg 2010;140:e45-e47.

14 Takagi $\mathrm{H}$, Matsui M, Umemoto T. Off-pump coronary artery bypass may increase late mortality: a meta-analysis of randomized trials. Ann Thorac Surg 2010;89:1881-8. 
Copyright 2017 BMJ Publishing Group. All rights reserved. For permission to reuse any of this content visit http://group.bmj.com/group/rights-licensing/permissions.

BMJ Case Report Fellows may re-use this article for personal use and teaching without any further permission.

Become a Fellow of BMJ Case Reports today and you can:

- Submit as many cases as you like

- Enjoy fast sympathetic peer review and rapid publication of accepted articles

Access all the published articles

- Re-use any of the published material for personal use and teaching without further permission

For information on Institutional Fellowships contact consortiasales@bmjgroup.com

Visit casereports.bmj.com for more articles like this and to become a Fellow 